\title{
Mortality Reporting and Rumor Generation: An Assessment of Crisis and Emergency Risk Communication Following Hurricane Maria in Puerto Rico
}

\author{
Elizabeth L. Andrade' ${ }^{1}$, Nicole D. Barrett, ${ }^{1}$ Mark C. Edberg, ${ }^{1}$ \\ Maria I. Rivera, ${ }^{2}$ Ljubica Latinovic, ${ }^{3}$ Matthew W. Seeger ${ }^{4}\left({ }^{\circ}\right.$, \\ Ann Goldman-Hawes, ${ }^{5}$ and Carlos Santos-Burgoa ${ }^{6}$
}

1. Department of Prevention and Community Health, Milken Institute School of Public Health, George Washington University, Washington, DC, USA

2. Rivera Group, Washington, DC, USA

3. Risk Communication and Community Engagement Senior Expert, Mexico

4. College of Fine, Performing \& Communication Arts, Wayne State University, Detroit, MI, USA

5. Department of Epidemiology and Biostatistics, Milken Institute School of Public Health, George Washington University, Washington, DC, USA

6. Department of Global Health, Milken Institute School of Public Health, George Washington University, Washington, DC, USA

\begin{abstract}
This study assessed the Government of Puerto Rico's crisis and emergency risk communications following Hurricane Maria and the post-disaster information environment to identify factors that may have contributed to negative public perceptions of mortality reports. Data included Government of Puerto Rico press releases, press conference audio recordings and Facebook Live transmissions, digital media news and social media commentary, and interviews with Government of Puerto Rico personnel and community stakeholders. Study findings indicate that inadequate crisis communication planning and training, coupled with information gaps and inconsistencies, contributed to rumors around the issue of mortality. As a consequence, the Government of Puerto Rico lost the ability to effectively manage messaging, thus decreasing
\end{abstract}

CONTACTS Elizabeth Andrade (D) · E-mail: elandrade@gwu.edu • Department of Prevention and Community Health, Milken Institute School of Public Health, George Washington University, 950 New Hampshire Avenue, NW, Suite 300, Washington, DC 20052 
their credibility, perceived transparency, and public trust. Recommendations regarding future preparedness activities and research are offered.

KEYWORDS: crisis communication, disasters, mortality, rumor generation

Hurricane Maria made landfall in Puerto Rico on September 20, 2017, as a Category 4 storm, causing widespread devastation and becoming the costliest tropical cyclone in Puerto Rican history (Scott, 2018). Numerous challenges to disaster response and recovery were exacerbated by multiple cascading failures in critical infrastructure and key resource sectors. Maria left millions of residents without electricity for weeks to months, and entire communities were isolated due to disrupted telecommunications, blocked roadways, and flooding (Federal Emergency Management Administration [FEMA], 2018). In this context, Government of Puerto Rico officials experienced difficulty providing timely and accurate information about hurricane-related deaths. Soon after the hurricane, the official death toll was widely questioned given the storm's severity, anecdotal evidence, and studies by outside groups estimating mortality of up to 72 times the official count of 64 deaths (Acosta \& Irizarry, 2018; Kishore et al., 2018; Pascual Sosa, 2017; Rivera \& Rolke, 2019; Robles et al., 2017; SantosLozada \& Howard, 2018). As evidence for a higher death toll mounted, so did the public's request for this issue to be addressed.

The George Washington University Milken Institute School of Public Health (GW SPH) was commissioned by the Government of Puerto Rico to conduct an independent study that included: (1) an epidemiological assessment of excess mortality; (2) a process evaluation of disaster context death certification; and (3) an assessment of the Government of Puerto Rico's crisis and emergency risk communication (CERC), with an emphasis on mortality reporting to the public. Here, we discuss the third component, with an overarching goal of identifying factors that may have contributed to controversy surrounding the death toll. To this end, we assessed the application of CERC guidelines by the Puerto Rican Government, in particular for public communication about mortality; examined the information environment in which mortality was conveyed; and explored Puerto Rican stakeholder perceptions regarding these communications. 


\section{Literature Review}

\section{Crisis and Emergency Risk Communication}

Communication with the public is a critical component of effective disaster preparedness, mitigation, response, and recovery (Centers for Disease Control [CDC], 2014; World Health Organization [WHO], 2005). Effective communication in disasters requires extensive planning and active management, and includes elements to establish public trust through information source credibility and transparency (Covello, 2003; Reynolds, 2006, 2011; Seeger, 2006; Steelman \& McCaffrey, 2013; S. Veil et al., 2008). Effective Media Communication during Public Health Emergencies lays out six recommended steps for effective media communication, and includes capacity assessment tools, such as the Internal Media Relations Assessment Tool and an Effective Media Communication Plan checklist (WHO, 2005). Further, there are guidelines in the Crisis and Emergency Risk Communication (CERC) manual (CDC, 2014), which outline principles of risk communication in crisis, and details other considerations, such as planning and the communication lifecycle; crisis stages; audiences, messages, and channels; spokespersons; human resources; and working with the media. However, the experiences of Hurricane Maria underscored the limitations of these guidelines when communicating about mortality after a catastrophic natural disaster.

\section{Information Vacuums and Public Perception in Disasters}

Regardless of established best practices and guidelines for communication, disasters present unique challenges given their inherent uncertainty, particularly in the case of catastrophic natural disasters (Seeger et al., 2018; Tinker \& Vaughan, 2010). In rapidly evolving disaster contexts, facts can be elusive. Communicators must have the capacity to adapt, especially when faced with limited availability of credible information, or an unmet "information sufficiency threshold" (Griffin et al., 2009; Seeger et al., 2018, p. 197). In disasters, these information vacuums create opportunities for the public to speculate, make inferences to explain gaps, question motives, generate rumors, or propagate unverified/false information, in an attempt to reconcile perceived incongruences (Hagar, 2013). 
In the absence of sufficient information, people tend to rely on their perceptions (Reynolds, 2011; Seeger, 2006; Seeger et al., 2018), as well as information sources they already trust and familiar channels (Savoia et al., 2013; Wray et al., 2008). Given the importance of public perception in disasters and the potential risks introduced by information vacuums, CERC planning and delivery should incorporate mitigation of any gaps between public perceptions and facts (Peters et al., 1997; Pornpitakpan, 2004; Ruggiero \& Vos, 2015). Nevertheless, while CERC guidelines address the correction of misinformation and misperceptions in the media, they do not adequately address how information vacuums, a phenomenon that is likely to occur following catastrophic events, should be handled by communicators after disasters.

\section{Navigating the Disaster Information Environment}

Inevitably, disaster communication exists within a larger disaster information environment, compelling communicators to monitor and interact with this environment (Savoia et al., 2017). An increasing number of studies highlight the impact that news media can have on public perceptions and behaviors in crises (Eckert et al., 2018; Parmer et al., 2016; Westerman et. al., 2014), demonstrating its potential to be leveraged for its broad public reach and familiarity (Littlefield \& Quenette, 2007; Reynolds \& Seeger, 2005). Social media networks have, in many cases, eclipsed traditional mass media as critical disaster information sources. As a rapid, two-way channel, social media has the potential to create disaster response transparency, enhance situational awareness, facilitate aid delivery, and crowd-verify or eliminate rumors (Hughes \& Palen, 2012; Yates \& Paquette, 2011). At the same time, not all disaster response agencies have established capacities to monitor public reactions and engage with stakeholders in real time through social media platforms. Consequently, these information-sharing networks can produce unprecedented challenges, such as the rapid propagation of misinformation, contributing to an information environment that can swiftly spin out of control (Liu et al., 2014). In these cases, organizations leading disaster response risk losing their ability to manage crisis messaging, potentially compromising response efforts (Reynolds, 2011; Seeger, 2006). 


\section{Communication of Disaster Mortality to the Public}

A key issue of public interest following disasters is mortality, especially since it is crucial to informing response and recovery efforts, policymaking, providing insight into population health status, and creating a broader understanding of the disaster's magnitude and impact (Checchi \& Roberts, 2005; Rickard et al., 2013; Salama et al., 2004; Santos-Burgoa et al., 2018). Notably, mortality also has the potential to become highly politicized following disasters (Checchi \& Roberts, 2008). Despite the importance of communicating to the public about disaster mortality, there is a scarcity of research in this area, and currently no consensus, on best practices for disaster mortality communication-it is here where the experiences of Hurricane Maria offer important lessons.

While disaster psychology and risk communication are established fields, efforts in the scientific and emergency management communities to systematically examine how the public processes and interprets disaster death counts or estimates are minimal. It is reasonable to think that lay audiences and media outlets may experience difficulty understanding methods used to determine disaster mortality (Lagassé et al., 2011; Reynolds, 2011; Seeger et al., 2003), which can be statistically complex and vary from one study to another. Nevertheless, these methods influence how mortality estimates can be interpreted given the assumptions and limitations of each approach (Hammer, 2018; Sandberg et al., 2019). This very scenario unfolded following Hurricane Maria, when the information environment became saturated with media coverage comparing the official death toll to numerous unofficial estimates, all using distinct methods, time periods, and populations at risk to produce mortality estimates (Sandberg et al., 2019). Yet, these death figures were compared without considering these important differences.

Following Hurricane Maria, journalists and the general public demanded that every lost life be counted, viewing this method as the most valid method of truly knowing how many died (Checchi \& Roberts, 2008). While it is appropriate to mourn every lost life following such a tragedy, this information can be difficult to obtain and verify in the immediate post-disaster period. This expectation of having timely and accurate hurricane-related death counts immediately following a catastrophic disaster represents a 
failure among scientists and communicators to convey the inherent superiority of excess mortality estimation over "body counts" in complex disaster scenarios where surveillance systems and death certification processes are disrupted (Checchi \& Roberts, 2008). Currently, there is little to guide communicators in making this distinction apparent to public audiences; while there is scientific literature related to mortality surveillance (Choudhary, 2012; Farag et al., 2013; Kim et al., 2017; Rocha et al., 2017; Seil et al., 2016) and documenting cause of death (Centre for Research on the Epidemiology of Disasters [CRED], 2016; Lakkireddy et al., 2004; Phillips et al., 2014; Wexelman et al., 2013), there is a paucity of studies exploring the specific concept of communicating disaster mortality to the public. There is no literature base that examines how death counts from a disaster should be communicated to the media, how to best explain information gaps that are common following disasters, how death counts may evolve post-disaster, or how to explain the science behind excess death estimates and what we can or cannot infer from these estimates. This research gap increases the likelihood that efforts in this area of communication will continue to be fraught with challenges if not addressed.

\section{Methods}

To understand factors that may have contributed to the death toll controversy, we used a multisource post-disaster CERC rapid assessment protocol to examine Government of Puerto Rico communications and spokesperson media interactions, how these interactions influenced the evolution of media coverage, and stakeholder perceptions of mortality reports. CERC and WHO guidelines informed the analytical framework described below (CDC, 2014; WHO, 2005).

\section{Data Collection and Analysis}

We collected data from five sources. We systematically reviewed 17 Government of Puerto Rico press releases and 20 press conferences (10 Facebook Live transmissions, 10 audio recordings) for the study period, September 20, 2017-February 28, 2018, to identify key messages and spokesperson delivery of mortality information (see Table 1). 
TABLE 1 Press Releases and Press Conferences

\begin{tabular}{|c|c|}
\hline $\begin{array}{l}\text { Data } \\
\text { Source }\end{array}$ & $\begin{array}{l}\text { Analytical Framework Source } \\
\text { Assessment Criteria }\end{array}$ \\
\hline \multirow{4}{*}{ 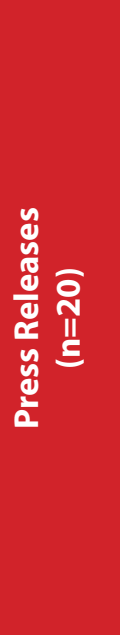 } & $\begin{array}{l}\text { WHO Effective Media Communication During Public Health } \\
\text { Emergencies handbook: } \\
\text { https://www.who.int/csr/resources/ } \\
\text { publications/WHO_CDS_2005_31/en/ }\end{array}$ \\
\hline & Press Release Content Included: \\
\hline & $\begin{array}{l}\text { (1) Key messages to the public; (2) Actions currently being taken; } \\
\text { (3) Actions that will be taken next; (4) How the public can help; } \\
\text { (5) Where to look for more information }\end{array}$ \\
\hline & $\begin{array}{l}\text { CDC CERC manual guidelines: https://emergency.cdc.gov/cerc/ } \\
\text { manual/index.asp adapted criteria, } 9 \text { Elements for Establishing } \\
\text { Trust and Credibility through Communications, p. 158; adapted } \\
\text { criteria, Spokesperson Pitfalls During an Emergency, p. } 160 \\
\text { WHO Effective Media Communication During Public Health } \\
\text { Emergencies handbook, Steps of Communication in Crisis }\end{array}$ \\
\hline \multirow[b]{3}{*}{ 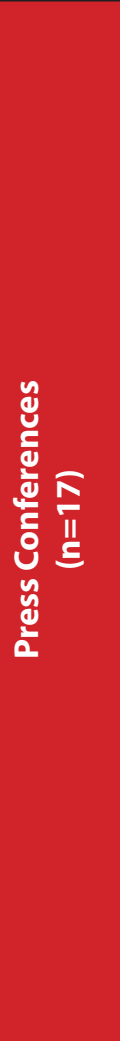 } & Content and Spokesperson Delivery included: \\
\hline & $\begin{array}{l}\text { 1. Expression of empathy (trust) } \\
\text { [Demonstrates empathy, caring, commitment-verbally and } \\
\text { in body language] } \\
\text { - When responding to a question or comment about loss of } \\
\text { any kind (death/injury) first expressed compassion, empathy, } \\
\text { caring? } \\
\text { - Acknowledged the validity of people's emotions? }\end{array}$ \\
\hline & $\begin{array}{l}\text { 2. Clarifying facts/call for action (credibility) } \\
\text { [What you know-in clear, key messages; Information is } \\
\text { accessible to all educational levels; Avoid professional jargon; } \\
\text { Information source expertise (education, role); Accuracy: } \\
\text { Accurate facts that have been confirmed; Consistency: } \\
\text { Consistent information] } \\
\text { - Delivered information in a clear manner? } \\
\text { - Used language appropriate for target audiences? } \\
\text { - Avoided the use of undefined jargon, acronyms and technical } \\
\text { language? } \\
\text { - Provided supporting facts for key messages? } \\
\text { - Used numbers, statistics and data effectively? } \\
\text { - Acted in partnership with credible third parties? } \\
\text { - Avoided going beyond the bounds of expertise? } \\
\text { - Made corrections quickly if errors were made? } \\
\text { - Provided consistent, coordinated information? }\end{array}$ \\
\hline
\end{tabular}




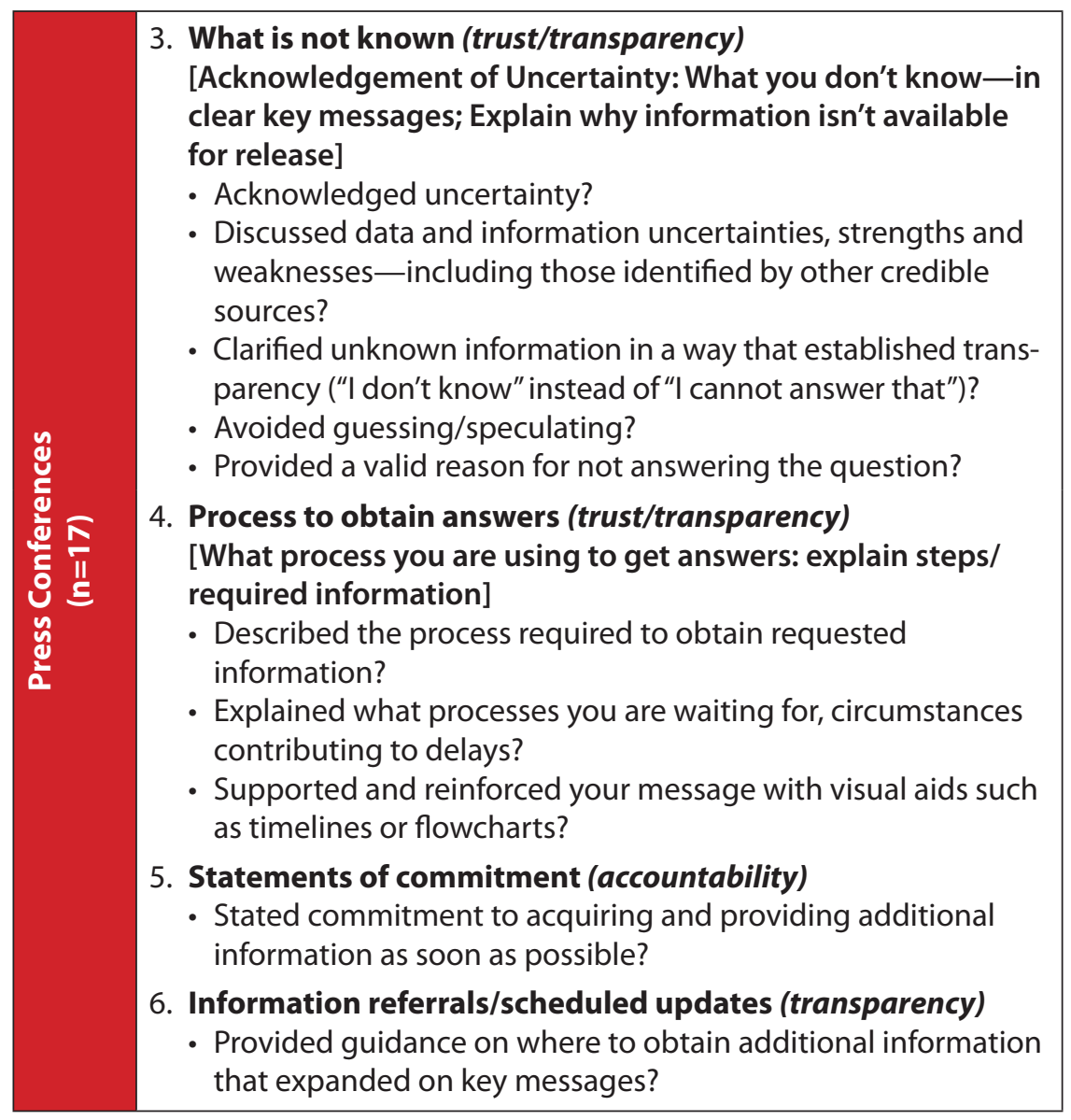

We conducted qualitative content analysis of press releases based on the extent to which they included information on hurricane mortality in five areas (Maxwell, 2009) (see Table 1): inclusion of mortality as a key message (and consistency of provided details); what was being done to assess mortality; what will be done to assess mortality; actions the public could take to assist; and where to look for more information. We also reviewed press conference proceedings based on criteria drawn from WHO and CDC guidelines (see Table 1). We assessed spokesperson delivery and content to determine the extent to which these criteria were met, thus contributing to the conceptual domains of trust, credibility, transparency, and accountability. For example, if spokespersons fail to describe steps being taken to determine mortality and 
provide vague responses about information they have about the death count, this may compromise perceptions of trust and transparency among public audiences.

To assess potential information environment influence on stakeholder perceptions of Government of Puerto Rico mortality reports, we systematically collected and reviewed 172 English- and Spanish-language digital media news reports and related social media commentary. We collected primary sources of information or stories from major U.S. mainland and Puerto Rican news outlets (e.g., CNN, Washington Post, New York Times, El Nuevo Día, LatinoUSA, among others). News articles $(\mathrm{n}=53)$ and social media posts were identified through web-based search engines (Google, Yahoo) and social media platforms (YouTube, $n=36$; Facebook, $\mathrm{n}=37$; and Twitter, $\mathrm{n}=46$ ) by systematically searching for predetermined keywords and hashtags (see Table 2).

TABLE 2 Digital Media News Reports \& Social Media Commentary

\begin{tabular}{|c|c|}
\hline $\begin{array}{l}\text { Data } \\
\text { Source }\end{array}$ & $\begin{array}{l}\text { Analytical Framework Source } \\
\text { Assessment Criteria }\end{array}$ \\
\hline \multirow{4}{*}{ 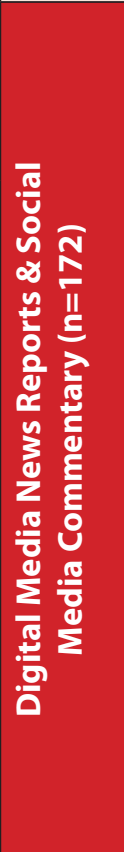 } & $\begin{array}{l}\text { CDC CERC manual guidelines, Working with Social Media Before } \\
\text { \& During a Crisis, p. } 268 \\
\text { WHO Effective Media Communication During Public Health Emer- } \\
\text { gencies handbook }\end{array}$ \\
\hline & $\begin{array}{l}\text { (1) Reasons and timing of mortality reports; (2) Appropriate } \\
\text { use of statistics; (3) Contradictory mortality data from official } \\
\text { spokespeople and unofficial sources; (4) Information used to } \\
\text { classify death as hurricane-related; (5) Explanations and illustra- } \\
\text { tions given for complex topics/processes; (6) Information gaps } \\
\text { filled by unofficial information; (7) Perceptions of the accuracy } \\
\text { and transparency of Government of Puerto Rico messages } \\
\text { regarding death figures }\end{array}$ \\
\hline & $\begin{array}{l}\text { Keywords/Phrases: Death toll Hurricane Maria; Deaths Hurricane } \\
\text { Maria Puerto Rico; Rosello death toll; Controversy death toll } \\
\text { Hurricane Maria; Deaths Hurricane Maria Puerto Rico; Muertos } \\
\text { Huracan Maria; Muertes Maria Puerto Rico }\end{array}$ \\
\hline & $\begin{array}{l}\text { Hashtags: \#PuertoRico \#HurricaneMaria \#puertoricohurricane } \\
\text { Maria \#PuertoRicoRelief \#PuertoRicoDeathToll \#Hurricane } \\
\text { MariaDeathToll \#HurricaneMariaDeaths }\end{array}$ \\
\hline
\end{tabular}


Digital media data collection captured mortality information destined for the public as it was introduced or changed to understand the chronology and information sharing dynamics. We conducted qualitative content analysis of digital media news and social media commentary to identify content in seven areas, related to domains of trust, credibility, transparency, and accountability (Maxwell, 2009) (see Table 2). For example, if in response to a news article suggesting that the official death toll was an undercount, the predominant commentary expressed the perception that the Puerto Rican Government was hiding information that would discredit their disaster response, we assessed that line of commentary to express perceptions of (non-) transparency and a lack of accountability.

Interviews were also conducted with 33 key informants, including 11 Puerto Rican Government personnel and 22 leaders representing stakeholder groups, during a 2-week period in April of 2018. Interviews helped characterize actions and events related to preparation and dissemination of mortality data, as well as stakeholder perceptions of the Government's mortality communications. Government personnel participants held key positions

TABLE 3 In-Depth Interviews

\begin{tabular}{|c|c|}
\hline $\begin{array}{l}\text { Data } \\
\text { Source }\end{array}$ & $\begin{array}{l}\text { Analytical Framework Source } \\
\text { Assessment Criteria }\end{array}$ \\
\hline \multirow{2}{*}{ 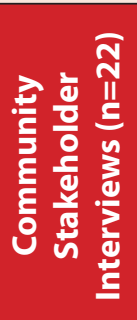 } & $\begin{array}{l}\text { CDC CERC manual guidelines, Stakeholder and Partner } \\
\text { Communication, p. } 241 \\
\text { WHO Effective Media Communication During Public Health Emer- } \\
\text { gencies handbook }\end{array}$ \\
\hline & $\begin{array}{l}\text { Qualitative thematic analysis, Perceptions of mortality reports- } \\
\text { in the domains of trust, transparency, accountability, credibility } \\
\text { (subdomains: expertise, accuracy, consistency) }\end{array}$ \\
\hline \multirow{2}{*}{ 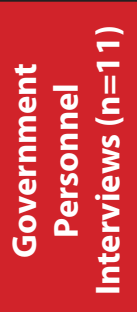 } & $\begin{array}{l}\text { CDC CERC manual guidelines, 9-step crisis communication plan and } \\
\text { process, p. 98; Working with Social Media Before and During a Crisis, } \\
\text { p. } 268 \\
\text { WHO Effective Media Communication During Public Health } \\
\text { Emergencies handbook }\end{array}$ \\
\hline & $\begin{array}{l}\text { Qualitative thematic analysis, Accounts of mortality reporting } \\
\text { communication processes }\end{array}$ \\
\hline
\end{tabular}


including heads of agencies or departments and communication leadership or staff. Community stakeholder participants included municipal mayors, community leaders, emergency responders, police, faith leaders, health care providers, non-profit organization staff, and funeral home directors, which were selected to represent all regions of Puerto Rico and exemplify a range of experiences given municipal diversity in socioeconomic status, political affiliation, demographics, and proximity to hospitals/clinics. We conducted interviews that lasted approximately 1 hour using a semi-structured protocol in Spanish. Interviews were audiorecorded and transcribed. Participants provided informed consent and protocols were IRB-approved. Shown in Table 3, we deductively and inductively coded transcripts using a procedure similar to the qualitative content analysis described above, and analyzed coded text to identify major themes representing participant response patterns. Coding was accomplished using NVivo version 11 software. As such, common and unique views and experiences among stakeholder and government personnel participants were elucidated (Bernard, 2005; Maxwell, 2009).

\section{Results}

Results are presented below, and organized into the following thematic areas: (1) CERC planning and coordination undertaken by the Government of Puerto Rico; (2) handling of mortality information gaps by the Government of Puerto Rico; (3) unofficial mortality reports in the information environment; and (4) Government of Puerto Rico CERC capacity, including spokesperson performance. Perceptions of Puerto Rico stakeholders are discussed throughout.

\section{CERC Planning and Coordination}

According to Government of Puerto Rico personnel participants, a number of factors created difficult circumstances for the teams responsible for CERC, mortality surveillance, and communication of mortality to the public. These circumstances stemmed from the devastation caused by Hurricane Maria, and also because a foundation for effective disaster communication was not in place. The 
Government of Puerto Rico did not have formal, written CERC plans at the time of the hurricane. As noted in our interviews:

... there was nothing [for CERC plans]. We were preparing-we had a couple of months saying this is what we need, these are the work groups. We had everything set up, and then boom [the hurricane hit].-Government of Puerto Rico Agency Leadership

Was there a written emergency communication plan before the hurricane? Not that I was aware of.-Government of Puerto Rico Agency Communication Leadership

According to agency leadership, Puerto Rico's emergency plan, and municipal emergency plans, was appropriate for a Category 1 hurricane, but not a catastrophic event. According to one member of the Government of Puerto Rico Agency Leadership:

... the plans in Puerto Rico were not prepared for a Category 5 hurricane. The plans in Puerto Rico are prepared for a Category 1 hurricane, which is really what we are used to having in Puerto Rico. So, now they have learned that the plan created many difficulties because neither the people were prepared for this [hurricane], nor the agencies either.

As a result, emergency plans did not include scenarios such as multiple cascading failures in critical infrastructure and key resource sectors, as specified in the Department of Homeland Security's National Planning Scenario (NPS) \#10, "Category 3 or Higher Hurricane." Mass media channels were largely unavailable, and Government personnel had not strategically planned to use alternative channels, such as radio or interpersonal communication, to coordinate public health or disaster response efforts. As various participants in our interviews noted:

We were almost completely incomunicado. There was only one radio station.-Community Leader

There was one [radio] station that worked during the hurricane ... it was the only media that there was, no cellular, no television, no electricity, and in terms of health information, on that station it was very general.-Non-profit Organization Personnel

... let's talk about leptospirosis. Well, I presented this issue directly to the Department of Health. There was no response to prevent cases. That never occurred. - Municipal Mayor 
Finally, communication contingencies that were implemented were inconsistent or ineffective. As one Municipal Mayor noted:

Communications? Bad ... satellite phones didn't work at all. I even remember when the personnel came to our municipality to demonstrate how the satellite phone worked, and they said to me, "Mayor, there's no way. What you will have to do is use it after midnight." And I said, "What do I need it for after midnight?" I think that for almost all of the mayors the satellite phone didn't work.

The lack of communication capabilities post-hurricane detracted from community members' perceived credibility of preparedness and response efforts. According to one community leader:

For me it was surprising to see people from emergency management that didn't have radio communication. I could not believe that in the middle of a hurricane, the most important people in Puerto Rico for managing disasters weren't prepared. So, the worst part of everything was the question of preparedness ... really, for us it showed complete ineptitude in this day and age ...

These factors related to planning and infrastructure collapse limited the Puerto Rican Government's ability to coordinate with municipalities and provide timely, reliable mortality information to the public. On one hand, Government personnel who were operating from the Center for Operations in Emergencies (COE) described a highly centralized process for preparing information destined for the public. This was reflected, for example, in the consistency between death counts given by spokespersons and press releases. However, communication personnel also noted challenges and delays in coordinating mortality data with municipalities, again related to infrastructure collapse and inadequate plans for effective contingencies. According to a member of the Government of Puerto Rico Agency Communication Leadership:

The problem with communication between municipalities and the central government was that there was no way to communicate efficiently. At first, the governor had [someone] going to all the municipalities each day to communicate. A lot of information was delayed. We were at the COE 24 hours and communication among us was 
continual. But, information wasn't flowing from municipalities. There should have been a designated liaison at each municipality to communicate with the central government instead of one person trying to reach all 78 municipalities.

Further complicating the communication of hurricane-related mortality to the public was the establishment of the Department of Public Safety (DPS) only months prior to hurricane season. This was the new umbrella for seven agencies related to emergency management, public safety, and forensic sciences. There are two agencies responsible for handling mortality data in Puerto Rico: (1) the Demographic Registry under the Department of Health (DOH), which is the final destination for all death records, and (2) the Bureau of Forensic Sciences, which is responsible for investigating any deaths suspected to be from unnatural causes, and had been recently shifted under the DPS umbrella. According to study participants, at the time of the hurricane, the transition to fully integrate this newly formed agency umbrella had not yet occurred, and this contributed to confusion about the delegation of responsibilities and processes underlying disaster mortality reporting. At the time of the hurricane, there was no updated, written protocol in place to coordinate release of information to the public between the two agencies. Upon creation of the DPS, decision-making changed for the timing and clearance of mortality data for the public, and one respondent perceived that the formal vetting process had been compromised.

Emergency plans for events with mass mortality always have a unified command, where there should be periodic meetings between the Department of Health, Bureau of Forensic Sciences, Department of Justice, Demographic Registry. Once the event happens, these meetings take place to make the decision about what information was going to be shared with the public. When the Department of Public Safety was created, an office which still hadn't been well-formed, the hurricane came. There was confusion because it wasn't Health that disseminated information on mass mortality, but instead DPS ... I think that information . . . it didn't pass formally through the Executive Committee because the process was disrupted, and there's another person requesting information, even though it wasn't through the official source.-Puerto Rico Government Agency Leadership 
Stakeholder respondents perceived this lack of coordination and protocol in mortality reporting as a $\mathrm{DOH}$ failure because shifts in agency responsibilities between the DPS and DOH were still not well-understood by community stakeholders. As noted by some of our participants:

It seems to me there wasn't a coordination protocol [for mortality surveillance] with the Department of Health.-Municipal Emergency Management Director

I went back to the Convention Center and intercepted the Secretary of Health, and I say to him, "Secretary, we have a situation with death certificates." I don't believe the Department of Health was as proactive as I expected ... what he said was: "Go to the Center of Operations and raise the issue." We went there and we raised the issue, went back two days later to search for a solution, but there still wasn't a solution.-Municipal Mayor

\section{Handling of Information Gaps}

Due to the devastation caused by Hurricane Maria and significant challenges to mortality surveillance, Government officials did not always have sufficient information to provide the public. Additionally, measures were not taken to explain these gaps or to monitor and counteract the spread of misinformation. The hurricane-related death count was typically not a key message in press conferences, and the Governor did not talk about the death toll unless asked specifically, after which he confirmed the official count in concordance with press releases or deferred to the Secretary of Public Safety. According to a review of press releases, beginning with the first official figure of six deaths on September 22, authorities clarified that more deaths were likely, but only those confirmed as hurricane-related would be reported, vaguely citing "safety personnel" as responsible for making this determination.

Based on a review of press materials, media coverage, and participant interviews, there was no overview given to the public to outline mortality surveillance or death certification processes. Spokespersons did not provide details or illustrations to facilitate an understanding of how these processes had been interrupted, and clarify reasons for delays or information gaps. As a member 
of the Government of Puerto Rico Agency Communication Leadership noted:

The public doesn't understand the process for certifying deaths. There should be a public awareness and education effort, and media should help convey this.

Government communications provided minimal information about the next steps they would take to ascertain hurricane-related deaths, and only two press releases on November 17 and 20 informed the public about what they could do to help.

Inconsistencies occurred in the provision of details for deaths and unexplained increases in deaths. In press releases on September 24 and 25, October 11, 12, 14, 20, and November 1, 2017, the Government provided specifics about causes and locations of deaths. However, press releases from October 5, 10, and 29 did not follow this format, and little to no detail was provided. After almost a week post-hurricane, in which the death toll remained unchanged at 16 , the controversy over mortality count transparency intensified when, after the U.S. President visited on October 3, the Governor of Puerto Rico announced that the death toll had risen from 16 to 34 . This coincided with President Trump's comments about the hurricane's limited impact, and also the abrupt change in the level of detail provided about deaths in press releases. Very little explanation was given to fill information gaps regarding this abrupt increase. When asked about the doubling death count on October 4, the Governor answered that the information they had before was insufficient, and that they are making sure to only count deaths certified as hurricane-related. There was no description of how mortality surveillance functions had been compromised, and as they began to be restored, that the public should anticipate a spike in mortality, a phenomenon known as the "Burkle Effect" (Burkle \& Greenough, 2008). It was not explained that this is an expected occurrence following complex and catastrophic disasters. The unexplained abrupt increase in deaths contributed to perceptions that the Government was manipulating death counts to avoid discrediting their disaster response, or evade blame. In one community leader's perception: 
The government made an error in not giving the correct number of deaths. I think they felt threatened that people would know that because of their negligence so many people died ... one of the things that you could tell from the media, when we finally had access, was the criticism was strong.

According to stakeholder respondents, this affected perceptions of transparency and credibility. According to two participants:

In giving that [death] report they weren't transparent, they weren't sincere with the public. Many of us understand that there's no reason to hide it. They probably wanted to clean their image ... I can't give a reason as to why they did it because I don't understand, but they weren't transparent.- Health Center Personnel

That is what made the public so uncomfortable-they are not telling the truth, lying. I saw this and was saying, but my God, what's happening? What do they want to hide?-Former Department of Health Personnel

The lack of clarity about the death certification process also persisted in media coverage, signaling a major impediment to an accurate count. Doctors and funeral home directors responding to media indicated that they did not have clear guidelines for death certification in disasters. Funeral directors noted that they had been authorized to proceed with cremations and burials if a death had been certified as unrelated to the hurricane. From September 20 to October 18 , there was a seemingly higher than usual authorization of cremations. According to DPS personnel, these cremations were misunderstood to represent hurricane-related deaths:

... the body would stay in the hospital if they died there. If they died at home and there was no electricity, they had to bury them. In order to bury someone, you had to request a permit and the Bureau of Forensic Sciences has to provide it. So, people opted to cremate because there wasn't time. That's why cremations during that time period increased. Also, it was cheaper. It had to be done . . . the increase in cremations created the perception that all people who were cremated died from the hurricane, but one thing has nothing to do with the other. 
Explanation of shifting trends in cremations were not provided to the public, opening space for misinterpretations, lingering suspicions, and questions about death reporting transparency. This potentially influenced public perceptions regarding the credibility of official death counts.

\section{Unofficial Mortality Reports in the Information Environment}

Numerous attempts were undertaken to employ alternative processes for identifying hurricane-related deaths. These investigative reports, scientific studies, and media interviews with mayors, health care professionals, and first responders, together with reporting of available figures from the Demographic Registry, created a confusing post-disaster information environment. Uncertainty regarding the official death count was echoed by stakeholder respondents, who perceived that the count should have been higher given their experiences. As one Municipal Police Commissioner and Emergency Management Director noted:

My town is small. Here we all know each other. Here there were weeks when I was saying, "My God, what is happening . . . every day someone dies!" I am sure mortality increased . . I assure you that the information being provided wasn't correct because I know my town. I can tell you that . . it was after the hurricane that it increased. It elevated to a very alarming figure.

The perception of an undercount led these stakeholders to conclude that government leadership was disconnected from the realities that communities throughout Puerto Rico were experiencing. For example, a Municipal Emergency Medical Director stated:

I believe that the impression they gave wasn't correct because I've always said that the number given was way below the reality ... the reality that I lived. My colleagues working with me and police that were in the street lived it. This reality wasn't lived by people who were tucked away in the Command Center there in San Juan. . . . they didn't live the community's reality ... you had to suffer that need...

Similarly, a Municipal Mayor noted, "I know, I have the numbers for my town, I don't know about the country, but I know that 
here, deaths almost doubled. I bury them. I open the gates of the cemetery." Some community leaders compared official mortality reports to media reports and calls on the radio about missing persons, which they perceived as credible firsthand sources of information. For example, in one community leader's perception:

That they hid information because you see the news and how people called the radio program saying that so-and-so is missing. Those people that went missing maybe died and were never found. It is understood that they died and that information the government doesn't offer as real.

\section{Crisis and Emergency Risk Communication Capacity}

In addition to the Government's lack of CERC plans, there had been insufficient pre-hurricane CERC training of communication personnel and official spokespersons, further limiting the likelihood that CERC best practices would be utilized. This lack of CERC training was apparent in spokesperson performance and study respondent indication of a lack of formal training for communication in disasters. As one government communications employee noted:

When they told me to report to the Center for Operations in Emergencies ... I had no idea what we were going to face. I had to face a phenomenon of great proportions, but didn't know what I was going to do there. I'm talking about even at the most basic, personal level of what to bring.

Following Hurricane Maria, there were few official spokespersons providing information to the public. The Governor initially conducted daily press conferences as the main spokesperson, although he was sometimes accompanied by others. He appeared to be prepared with relevant talking points, which aligned with press releases. He seemed to listen carefully to questions and responded without using overly technical language. To some extent, he managed uncertainty by saying what was known, identifying what was still being reviewed, and indicating willingness to provide information when available. However, when asked about deaths, he often deferred to the Secretary of Public Safety instead of a subject matter expert. 
The Secretary of Public Safety was also a prominent spokesperson. In his interactions with the media, he delivered concise information, conveyed authority, acknowledged uncertainty in the mortality count, and also indicated a willingness to provide more information when available. However, he provided very limited responses to media questions, and in some cases, contradictory information. When asked about mortality, his responses tended to be relatively limited, such as "We are still reviewing" or "as soon as we get more data," with no specifics provided about what was still being reviewed, who was reviewing it, what type of data they were waiting for, or why there were delays. Further, while maintaining on numerous occasions that the government would not be influenced by anecdotes or assumptions, he stated in a press appearance on November 8 that there could be an increase of $30 \%$ in the average daily deaths. No details were provided to validate this statistic, which conflicted with previous statements, including one on October 1, when he speculated that deaths could increase "exponentially." The ineffective use of statistics and suppositions may have influenced perceived credibility.

Both the Governor and the Secretary of Public Safety failed to defer to subject matter experts early in the post-disaster period to answer questions about mortality surveillance and death certification. It was not until November 8 that the Secretary of Public Safety called upon representatives from the Bureau of Forensic Sciences and the Demographic Registry to discuss these processes and respond to public inquiry. This coordination with subject matter experts occurred too late. By that time, there were already inconsistencies and rumors circulating in the information environment, as well as growing stakeholder frustration.

The credibility of official messages was also called into question with reports of contradictory or unconfirmed statements by other public officials. One example was the Mayor of San Juan's response to the Secretary of Homeland Security, stating that the death count could be 10 times higher than official data. The Secretary of Public Safety characterized this statement as "irresponsible," but did not offer corrections. In a media interview on September 28, the Puerto Rican Secretary of Health acknowledged that some 
hospital morgues were full. According to one funeral home director respondent, this contributed to misconceptions since deaths occur daily regardless of disasters:

We are more or less the same right now [in April, 2018]-there has not been an increase [in deaths]. People have the perception that many more people died . . . because in a hospital there are 10 deaths a day, and funeral homes claim those bodies immediately ... but if funeral homes cannot go ... tomorrow they have 20 and the next day they have 30 ... there is a perception that there are more deceased than there are.

However, the Secretary of Health gave no explanation to contextualize morgue capacity. This information vacuum opened an opportunity for misconceptions about hurricane-related deaths.

The Secretary of Health also provided mortality data that had not yet been formally incorporated into the official death count. For example, in the interview on September 28, he indicated that there were seven additional deaths at hospitals, but the cause of death was pending; yet the official death toll was 16 . The release of such unconfirmed, contradictory information may have influenced public perceptions of credibility and transparency.

\section{Limitations}

Several limitations should be considered when interpreting study findings. Data was collected 7 months post-hurricane, introducing potential recall bias in respondent accounts. Additionally, we undertook a rapid assessment with a condensed study timeline, limiting the digital media that could be reviewed and the interview sample size. We did, however, focus our digital media review on pivotal points in the availability of information, and interviewed a number of key actors within the Government who were involved in mortality data management or communication. Furthermore, we recruited interview respondents with diversity in a number of criteria that were likely to affect a community's experiences with the hurricane. Regardless of the sample size, we reached saturation. 


\section{Discussion}

The days and weeks following Hurricane Maria were characterized by widespread criticism of the Government of Puerto Rico's handling of mortality reporting. In addition to the hurricane's aftermath, there was also a crisis of death toll uncertainty. Not only did this issue dominate discourse, detracting from other important issues post-hurricane, it also raised key questions about planning for similar complex disasters. The experiences of Hurricane Maria highlighted areas of prospective research and practice that should be prioritized by scientific and disaster communities, and signaled areas related to disaster impact communication that should be expanded upon in CERC guidelines-mortality communication and communicating in catastrophic disaster contexts.

\section{CERC Guidelines and Information Vacuums}

One goal of communication in disasters is to provide accurate, timely information to the public. According to CERC and WHO guidelines (CDC, 2014; WHO, 2005), government administrations and disaster response organizations can build public confidence by having coordinated, transparent information sharing, and trained spokespersons and subject matter experts to provide consistent information and explanations. The Government faced difficulties communicating about mortality, stemming from a lack of CERC plans and the timing of recent government restructuring that complicated coordination. These challenges were exacerbated by not anticipating widespread infrastructure failures and a lack of communicator CERC training.

Another goal of communication in disasters is to minimize misinformation, which includes monitoring the information environment and counteracting rumors (Liu et al., 2014; Savoia et al., 2017; Seeger, 2006). Following Hurricane Maria, the politicization of the death count resulted in part from information gaps coupled with insufficient monitoring and rumor control. Major interruptions to mortality surveillance resulted in delayed reporting and a substantial information vacuum. Official and unofficial mortality reports proliferated in the media to fill this void, contributing to stakeholder perceptions that questioned credibility and 
transparency of the Government of Puerto Rico. In the context of waning public trust, overall disaster response capabilities can become greatly diminished.

Additionally, Government of Puerto Rico personnel did not recount efforts to engage with stakeholders on social media or systematically monitor this digital information environment as part of an overarching communication strategy. Official press conferences were streamed on the Governor's Facebook Live account, but there were no coordinated efforts taken to monitor and respond to misinformation or rumors. Given the potential of social media for disseminating verified information and minimizing the spread of rumors, this was a missed opportunity. Practitioners engaged in disaster preparedness planning should integrate social media use into daily operations, dedicating personnel to facilitating stakeholder relationships, and monitoring and responding to public reactions during crisis.

Situations also arose following the hurricane that were inadequately explained by spokespersons. These information gaps created opportunities for the public to question the Government's motives and speculate as to why the information was unavailable, when it was not necessarily a question of motive. Even in the absence of timely mortality data, the processes of mortality surveillance and death certification could have been described and barriers to these processes detailed. These occurrences following Hurricane Maria raise the question about how governments and disaster response organizations can adequately prepare to communicate in catastrophic disasters, where the likelihood of information vacuums is high, mortality surveillance is at risk for disruption, and high levels of public interest and media coverage can be anticipated. An important consideration is how information vacuums should be handled; however, while CERC guidelines address the correction of misinformation and misperceptions in the media, they do not elaborate on how information vacuums should be handled by disaster communicators. Furthermore, CERC guidelines delineating communication plan design and implementation do not address catastrophic disaster situations, when the communication landscape drastically changes and contingencies are required to maintain communication functions. 
Drawing from lessons learned following Hurricane Maria, current CERC guidelines should be expanded to address these important areas. With guidelines for communicating following catastrophic disasters, planning can be undertaken to anticipate factors such as elevated mortality yet disrupted mortality surveillance systems, information vacuums accompanied by intense media interest, and toppled communication infrastructure necessitating contingencies. With catastrophic CERC guidelines, communicators following Hurricane Maria would have been better positioned to prepare for substantial information vacuums and address them more effectively through messaging and responding to the rapidly evolving information environment; have communication plans and contingencies in place to enable information sharing and message coordination, including with local stakeholders throughout Puerto Rico; and anticipate mortality as a key point of public interest and vital piece of information for disaster responders and policymakers.

\section{Communicating Post-Disaster Mortality}

Risks to credibility, trust, and transparency can be mitigated in part by having spokespersons who are highly trained in the subject matter, and who place as much importance on the message itself as the manner in which the message is communicated. CERC and WHO recommendations detail considerations of spokesperson selection, characteristics, and training. CERC and WHO guidelines also highlight the importance of delivering early messaging from information sources that build credibility through illustrative descriptions for complex topics, background information, supporting facts, third-party validations, and explanations of situations that may be questioned by the public. While Government of Puerto Rico spokespersons were experienced in public speaking, the lack of CERC media training was notable. This was evidenced by spokesperson performance during press conferences and media interviews, as well as accounts from study participants who indicated that they had not been trained in disaster communication. Spokesperson missteps, including vague responses when asked about disaster mortality, the use of inconsistent statistics, 
speculation about anticipated mortality counts, late involvement of subject matter experts in press conferences, lack of supportive materials to explain death certification, communication of deaths to the media that had not yet been confirmed as hurricane-related, and inconsistent messaging between official spokespersons, created a post-disaster information environment saturated with criticism and diminished credibility of the Government of Puerto Rico's efforts.

Future disaster preparedness efforts should emphasize spokesperson and communication personnel training related to mortality surveillance processes and communicating with the public about mortality, especially following catastrophic events. This raises the questions: What is the best way to communicate with the public about disaster mortality, and what do we know about how public audiences understand and interpret mortality estimates? The current CERC and WHO guidelines do not include a nuanced discussion of communicating disaster mortality to the public. Future research should explore these areas in order to inform best practices.

\section{Conclusion}

The response and recovery period following Hurricane Maria was punctuated by significant controversy surrounding mortality reporting. Puerto Rican Government officials provided information they had available to them at the time and made attempts to be open and transparent. Given the level of destruction experienced in Puerto Rico, it is likely that delays in mortality surveillance and temporary information gaps were inevitable. However, given these circumstances, not applying CERC best practices and inadequate CERC training led to unexplained information gaps and inconsistencies that contributed to rumors and controversy. Confusion was intensified by numerous unofficial death counts in the information environment. Ultimately, the Government of Puerto Rico lost the ability to effectively manage messaging, thus decreasing their source credibility, perceived transparency, and public trust. While an essential role of government in disasters is to protect the 
public from risk, the mortality count controversy drained political capital and detracted from efforts to meet population health and safety needs.

These experiences highlight the importance of CERC planning and training, which should be expanded to include guidelines for disasters of catastrophic scale where key resources and infrastructure are impacted, communication channels are similarly degraded, and information vacuums are likely to occur. Future research should examine the role of a robust CERC response in disaster communications, as well as examine application of the CERC model across diverse disasters and contexts, including those with considerable resource constraints (Avery, 2019). These occurrences also emphasize the need for more impact communication research, or communicating to the public about a disaster's impact, including mortality. Little is known about how audiences process disaster mortality information. Consensus in this area will inform development of anticipatory educational materials, spokesperson training and key messages, guidelines for intersectoral and stakeholder collaboration, and recommendations for navigating the post-disaster information environment.

\section{Archived links from Table 1}

CDC CERC manual guidelines. Retrieved from web archive:

https://web.archive.org/web/20190614141121/https://emergency. cdc.gov/cerc/manual/index.asp

WHO Effective Media Communication During Public Health Emergencies handbook. Retrieved from web archive:

https://web.archive.org/web/20190418231742/https://www.who. int/csr/resources/publications/WHO_CDS_2005_31/en/

\section{ORCID}

Elizabeth Andrade (1) https://orcid.org/00oo-0001-7652-1337

Matthew Seeger (1) https://orcid.org/oooo-0002-5585-3081 


\section{References}

Acosta, R. J., \& Irizarry, R. A. (2018, September). Post-Hurricane vital statistics expose fragility of Puerto Rico's health system. https://doi.org/10.1101/407874

Avery, E. J. (2019). The effects of community size, control over agenda, and contextual variables on zika virus preparation of public information officers at local public health departments. Journal of International Crisis and Risk Communication Research, 2(1), 97-119. https://doi.org/10.30658/jicrcr.2.1.5

Bernard, H. R. (2005). Research methods in anthropology: Qualitative and quantitative approaches (4th ed.). Altamira Press.

Burkle, F. M., \& Greenough, P. G. (2008). Impact of public health emergencies on modern disaster taxonomy, planning, and response. Disaster MedicineandPublic HealthPreparedness, 2 (3), 192-199. https://doi.org/10.1097/DMP.obo13e3181809455

Centers for Disease Control and Prevention. (2014). Crisis and Emergency Risk Communication Manual. Retrieved from web archive: https://emergency.cdc.gov/cerc/manual/index.asp

Centre for Research on the Epidemiology of Disasters. (2016, October). Poverty and Death: Disaster Mortality. Retrieved from web archive: https://web.archive.org/save/https://www. unisdr.org/we/inform/publications/50589

Checchi, F., \& Roberts, L. (2005). HPN Network Paper 52: Interpreting and using mortality data in humanitarian emergencies: A primer for non-epidemiologists. Overseas Development Institute. Retrieved from https://odihpn.org/ wp-content/uploads/2005/o9/networkpapero52.pdf

Choudhary, E., Zane, D. F., Beasley, C., Jones, R., Rey, A., Noe, R. S., Martin, C., Wolkin, A. F., \& Bayleyegn, T. M. (2012). Evaluation of active mortality surveillance system data for monitoring hurricane-related deaths-Texas, 2008. Prehospital Disaster Medicine, 27(4), 92-97. https://doi.org/10.1017/ $\mathrm{S}_{1049023 \mathrm{X} 12000957}$

Covello, V. T. (2003). Best practices in public health risk and crisis communication. Journal of Health Communication, 8( $\left.\mathrm{S}_{1}\right), 5-8$. https://doi.org/10.1080/713851971 
Eckert, S., Sopory, P., Day, A., Wilkins, L., Padgett, D., Novak, J., Noyes, J., Allen, T., Alexander, N., Vanderford, M., \& Gamhewage, G. (2018). Health-related disaster communication and social media: Mixed-method systematic review. Health communication, 33(12), 1389-1400. https://doi.org/10 $.1080 / 10410236.2017 .1351278$

Farag, N. H., Rey, A., Noe, R., Bayleyegn, T., Wood, A., \& Zane, D. (2013). Evaluation of the American Red Cross disaster-related mortality surveillance system using Hurricane Ike data-Texas 2008. Disaster Medicine and Public Health Preparedness, 7(1), 13-19. https://doi.org/10.1001/dmp.2012.54

Federal Emergency Management Administration. (2018, July). 2017 Hurricane Season FEMA After-Action Report. Retrieved from https://www.fema.gov/media-library/assets/documents/ 167249

Griffin, R. J., Neuwirth, K., Dunwoody, S., \& Giese, J. (2009). Information sufficiency and risk communication. Media Psychology,6(1),23-61.https://doi.org/10.1207/s1532785xmep 0601_2

Hagar, C. (2013). Information vacuums. In K. B. Penuel, M. Statler, \& R. Hagen (Eds.), Encyclopedia of Crisis Management, 527529. Sage Publications.

Hammer, C. C. (2018). Understanding excess mortality from not-so-natural disasters. Lancet Planetary Health, 2(11), 471472. https://doi.org/10.1016/S2542-5196(18)30222-5

Hughes, A. L., \& Palen, L. (2012). The evolving role of the public information officer: An examination of social media in emergency management. Journal of Homeland Security and Emergency Management, 9(1), 1547-7355. https://doi. org/10.1515/1547-7355.1976

Kim, S., Kulkarni, P. A., Rajan, M., Thomas, P., Tsai, S., Tan, C., Davidow, A. (2017). Hurricane Sandy (New Jersey): Mortality rates in the following month and quarter. American Journal of Public Health, 107(8), 1304-1307. https://doi.org/10.2105/ AJPH.2017.303826 
Kishore, N., Marqués, D., Mahmud, A., Kiang, M. V., Rodriguez, I., Fuller, A., Sorensen, C., Racy, F., Lemery, J., Maas, L., Leaning, J., Irizarry, R., Balsari, S., \& Buckee, C. O. (2018). Mortality in Puerto Rico after Hurricane Maria. New England Journal of Medicine, 379(2), 162-70. https://www.nejm.org/ doi/full/10.1056/NEJMsa1803972

Lagassé, L. P., Rimal, R. N., Smith, K. C., Storey, J. D., Rhoades, E., Barnett, D. J., Omer, S. B., \& Links, J. (2011). How accessible was information about $\mathrm{H}_{1} \mathrm{~N}_{1}$ flu? Literacy assessments of CDC guidance documents for different audiences. PLoS One, 6(10), e23583. https://doi.org/10.1371/journal.pone.0023583

Lakkireddy, D. R., Gowda, M. S., Murray, C. W., Basarakodu, K. R., \& Vacek, J. L. (2004). Death certificate completion: How well are physicians trained and are cardiovascular causes overstated? American Journal of Medicine, 117(7), 492-498. https:// doi.org/10.1016/j.amjmed.2004.04.018

Littlefield, R. S., \& Quenette, A. M. (2007). Crisis leadership and Hurricane Katrina: The portrayal of authority by the media in natural disasters. Journal of Applied Communication Research, 35(1), 26-47. https://doi.org/10.1080/00909880601065664

Liu, F., Burton-Jones, A., \& Xu, D. (2014). Rumors on social media in disasters: Extending transmission to retransmission. Pacific Asia Conference on Information Systems 2014 Proceedings. Retrieved from web archive: https://web. archive.org/web/20170809110153/http://www.pacis-net.org/ file/2014/2209.pdf

Maxwell, J. A. (2009). Designing a qualitative study. In L. Bickman, \& D. Rog (Eds.), The sage handbook of applied social research methods (2nd ed.), 214-253. SAGE Publications, Inc.

Parmer, J., Baur, C., Eroglu, D., Lubell, K., Prue, C., Reynolds, B., \& Weaver, J. (2016). Crisis and emergency risk messaging in mass media news stories: Is the public getting the information they need to protect their health? Health Communication, 31(10), 1215-1222. https://doi.org/10.1080/10410236.2015.1049728 
Pascual Sosa, O. (2017, December). Nearly 1,00o more people died in Puerto Rico after Hurricane Maria. Latino USA. Retrieved from web archive: https://web.archive.org/web/20190918204 817/https://www.latinousa.org/2017/12/o7/nearly-100opeople-died-puerto-rico-hurricane-maria/

Peters, R. G., Covello, V. T., \& McCallum, D. B. (1997). The determinants of trust and credibility in environmental risk communication: An empirical study. Risk Analysis, 17(1), 43-54. https://doi.org/10.1111/j.1539-6924.1997.tboo842.X

Phillips, D. E., Lozano, R., Naghavi, M., Atkinson, C., GonzalezMedina, D., Mikkelsen, L., Murry, C. JL., Lopez, A. D. (2014). A composite metric for assessing data on mortality and causes of death: The vital statistics performance index. Population Health Metrics, 12(14), 1-16. https://doi.org/10.1186/14787954-12-14

Pornpitakpan, C. (2004). The persuasiveness of source credibility: A critical review of five decades' evidence. Journal of Applied Social Psychology, 34(2), 243-281. https://doi. org/10.1111/j.1559-1816.2004.tbo2547.x

Reynolds, B. J. (2006). Crisis and Emergency Risk Communication. Centers for Disease Control and Prevention. https://emergency. cdc.gov/cerc/resources/pdf/cerc_2014edition.pdf

Reynolds, B. J. (2011). When the facts are just not enough: Credibly communicating about risk is riskier when emotions run high and time is short. Toxicology and Applied Pharmacology, 254(2), 206-214. https://doi.org/10.1016/j.taap.2010.10.023

Reynolds, B. J., \& Seeger, M. W. (2005). Crisis and emergency risk communication as an integrative model. Journal of Health Communication, 10(1), 43-55. https://doi. org/10.1080/10810730590904571

Rickard, L. N., McComas, K. A., Clarke, C. E., Stedman, R. C., \& Decker, D. J. (2013). Exploring risk attenuation and crisis communication after a plague death in Grand Canyon. Journal of Risk Research, 16(2), 145-167. https://doi.org/10.1080/1366 9877.2012 .725673 
Rivera, R., \& Rolke, W. (2019). Modeling excess deaths after a natural disaster with application to Hurricane Maria. Statistics in Medicine, 38, 4545-4554. https://www.ncbi.nlm.nih.gov/ pubmed/31321799

Robles, F., Davis, K., Fink, S., \& Almukhtar, S. (2017, December). Official toll in Puerto Rico: 64. Actual deaths may be 1,052. The New York Times. https://nytimes.com/interactive/2017/12/08/ us/puerto-rico-hurricane-maria-death-toll.html

Rocha, L. A., Fromknecht, C. Q., Redman, S. D., Brady, J. E., Hodge, S. E., \& Noe, R. S. (2017). Medicolegal death scene investigations after natural disaster- and weather-related events: A review of the literature. Academic Forensic Pathology, 7(2), 221-239. https://doi.org/10.23907/2017.023

Ruggiero, A., \& Vos, M. (2015). Communication challenges in CBRN terrorism crises: Expert perceptions. Journal of Contingencies and Crisis Management, 23(3), 138-148. https:// doi.org/10.1111/1468-5973.12065

Salama, P., Spiegel, P., Talley, L., \& Waldman, R. (2004). Lessons learned from complex emergencies over past decade. Lancet, 364(9447), 1801-1813. https://doi.org/10.1016/So1406736(04)17405-9

Sandberg, J., Santos-Burgoa, C., Roess, A., Goldman-Hawes, A., Pérez, C., Garcia-Meza, A., \& Goldman, L. (2019). All over the place? Differences in and consistency of excess mortality estimates in Puerto Rico after hurricane Maria. Epidemiology, 3o (4), 549-552. https://doi.org/10.1097/ede.0000000000000970

Santos-Burgoa, C., Sandberg, J., Suarez Perez, E. L., GoldmanHawes, A., Zeger, S., Garcia Meza, A. M., Perez, C. M., Estrada-Merly, N., Colon-Ramos, U., Nazario, C. M., Andrade, E., Roess, A., \& Goldman, L. R. (2018). Assessment of excess mortality from Hurricane Maria in Puerto Rico: Modeling its time series, and differential and persistent risk. Lancet Planetary Health, 2(11), 478-488. https://doi.org/10.1016/ S2542-5196(18)30209-2

Santos-Lozada, A. R., \& Howard, J. T. (2018). Use of death counts from vital statistics to calculate excess deaths in Puerto Rico following Hurricane Maria. Journal of American Medical Association, 320(14), 1491-1493. https://doi.org/10.1001/ jama.2018.10929 
Savoia, E., Lin, L., \& Gamhewage, G. M. (2017). A conceptual framework for the evaluation of emergency risk communications. American Journal of Public Health, 107(suppl 2), S208S214. https://doi.org/10.2105/AJPH.2017.304040

Savoia, E., Lin, L., \& Viswanath, K. (2013). Communications in public health emergency preparedness: A systematic review of the literature. Biosecurity and Bioterrorism: Biodefense Strategy, Practice, and Science, 11(3), 170-184. https://doi.org/10.1089/ bsp. 2013.0038

Scott, M. (2018, August). Hurricane Maria's devastation of Puerto Rico. National Oceanic and Atmospheric Administration. Retrieved from web archive: https://web.archive.org/web/ $20190620142000 /$ https://www.climate.gov/news-features/ understanding-climate/hurricane-marias-devastationpuerto-rico

Seeger, M. W. (2006). Best practices in crisis communication: An expert panel process. Journal of Applied Communication Research, 34(3), 232-244. https://doi.org/ 10.1080/00909880600769944

Seeger, M. W., Pechta, L. E., Price, S. M., Lubell, K. M., Rose, D. A., Sapru, S., Chansky, M. C., Smith, B. J. (2018). A conceptual model for evaluating emergency communication in public health. Health Security, 16(3), 193-203. https://doi. org/10.1089/hs.2018.0020

Seeger, M. W., Sellnow, T. L., \& Ulmer, R. R. (2003). Communication and organizational crisis. Praeger.

Seil, K., Spira-Cohen, A., \& Marcum, J. (2016). Injury deaths related to Hurricane Sandy, New York City, 2012. Disaster Med Public Health Preparedness, 10(3), 378-385. https://doi. org/10.1017/dmp.2016.36

Steelman, T. A., \& McCaffrey, S. (2013). Best practices in risk and crisis communication: Implications for natural hazards management. Natural Hazards, 65(1), 683-705. https://doi. org/10.1007/s11069-012-0386-Z 
Tinker, T. L., \& Vaughan, E. (2010). Risk and crisis communication: Best practices for government agencies and non-profit organizations. Booz, Allen, Hamilton. Retrieved from https:// www.worldcat.org/title/risk-and-crisis-communicationsbest-practices-for-government-agencies-and-non-profitorganizations/oclc/702675958

Veil, S., Reynolds, B., Sellnow, T. L., \& Seeger, M. W. (2008). CERC as a theoretical framework for research and practice. Health Promotion Practice, 9(4 suppl), 26S-34S. https://doi. org/10.1177/1524839908322113

Westerman, D., Spence, P. R., \& Van Der Heide, B. (2014). Social media as information source: Recency of updates and credibility of information. Journal of Computer-Mediated Communication, 19(2), 171-183. https://doi.org/10.1111/ jcc4.12041

Wexelman, B. A., Eden, E., \& Rose, K. M. (2013). Survey of New York City resident physicians on cause-of-death reporting, 2010. Preventing Chronic Disease, 10(76), 1-12. https://doi. org/10.5888/pcd10.120288

World Health Organization. (2005). Effective media communication during public health emergencies handbook. Retrieved from web archive: https://web.archive.org/web/20190628202440/ http://www.who.int/csr/resources/publications/WHO_ CDS_2005_31/en/

Wray, R., Becker, S., Henderson, N., Gilk, D., Jupka, K., Middleton, S., Druy, A., \& Mitchell, E. W. (2008). Communicating with the public about emerging health threats: Lessons from the pre-event message development project. American Journal of Public Health, 98(12), 2214-2222. https://doi.org/10.2105/ AJPH.2006.107102

Yates, D., \& Paquette, S. (2011). Emergency knowledge management and social media technologies: A case study of the 2010 Haitian earthquake. International Journal of Information Management, 31(1), 6-13. https://doi.org/10.1016/j.ijinfomgt. 2010.10.001 

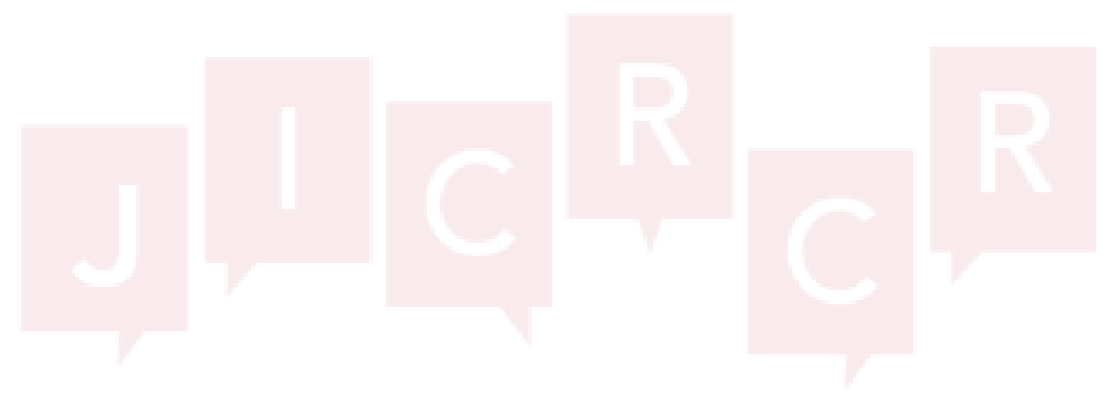